\title{
Design and Simulation of Metamaterial based Circularly Polarized Antenna Array
}

\author{
Rohini G.Bhatkoorse ${ }^{1}$, Dr. Mahesh $\mathrm{A}^{2}$ \\ ${ }^{1} P G$ student, Department of Electronics and Communication \\ ${ }^{2}$ Associate Professor, Department of Electronics and Communication \\ $R V$ College of Engineering, Bengaluru, India \\ ${ }^{1}$ Email: rohinigb.lcs19@rvce.edu.in \\ ${ }^{2}$ Email: mahesha@rvce.edu.in
}

\begin{abstract}
The microstrip patch array antenna is usually designed as a broadside radiator. The radiating area of the patch can be of any planar shape from elliptical to square, but rectangular is preferred over other shapes. When elements of antenna are repeated, it is called as an array of antennas. When the distance between antennas is reduced, mutual coupling effect occurs. This effect occurs when the distance between the antennas is less than $0.5 \lambda$ and this affects the gain and efficiency of the antennas. This effect can be reduced by using metamaterials. To reduce the mutual coupling between the antenna elements the metamaterial structure is artificially designed to obtain negative permittivity and permeability using HFSS and the results are verified using MATLAB. These metamaterials are placed between the patch elements of $1 \times 2$ circularly polarized array antenna when the distance between the patches is $0.2 \lambda$ for both $R T$ duroid and FR4 epoxy substrate for $5 \mathrm{GHz}$ resonant frequency.
\end{abstract}

Keywords: Permittivity, Permeability, Refractive index, Mutual Coupling, Metamaterials, Circular polarization.

\section{INTRODUCTION}

A microstrip patch antenna is a metallic strip or patch mounted on a dielectric layer (substrate) over a ground plane. The patch antenna is used for high performance in extreme applications like aircraft, satellite, missiles, cellphones and electronic devices. The characterization of antennas suggests that the radiation pattern of a microstrip element is relatively wide and provides gain of $5-7 \mathrm{~dB}$. A method to increase the dimensions of the structure, without enlarging the size of the patch is to form repeating units of radiating elements. This new antenna, formed by multi-elements, is referred to as an array. To reduce the mutual coupling effect between the patch elements, various methods are used in which usage of metamaterial is one of the methods. Metamaterials are artificially designed for specific purposes for changing the dimensions of the structure with respect to the frequency required. Another advantage is that the mathematical analysis is faster and easier due to the existing equations. In this paper, the diagonally truncated split ring resonator (DTSRR) is used as a metamaterial structure.

\section{DESIGN OF A DTSRR METAMATERIAL UNIT CELL}

The DTSRR metamaterial unit cell is designed at $5 \mathrm{GHz}$ resonant frequency using RT duroid and FR4 epoxy substrate is shown in Figure 1. The dimensions of the unit cell are optimized through iterations to observe the negative permittivity and permeability is as described in Table 1.

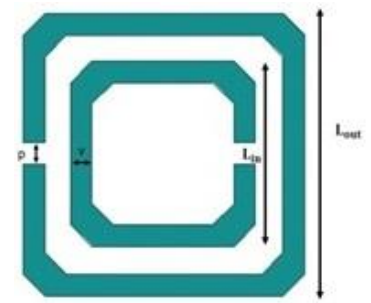

Figure 1: Structure of DTSRR 


\begin{tabular}{|c|c|c|}
\hline Dimensions & $\begin{array}{c}\text { For RT Duroid } \\
\text { substrate (in mm) }\end{array}$ & $\begin{array}{c}\text { For FR4 epoxy } \\
\text { substrate (in mm) }\end{array}$ \\
\hline L_out & 5.25 & 4.55 \\
\hline L_in & 3.45 & 2.75 \\
\hline p & 0.4 & 0.4 \\
\hline v & 0.8 & 0.8 \\
\hline
\end{tabular}

To extract the metamaterial parameters such as refractive index $(\eta)$, permittivity $(\epsilon)$ and permeability $(\mu)$ from S-parameters obtained from HFSS simulation of DTSRR is done by using S-parameter retrieval method. The parametric values of DTSRR cell are negative at $5 \mathrm{GHz}$ and are presented in Table 2, which indicates the double negative metamaterial behavior.

Table 2: Parameters of DTSRR unit cell

\begin{tabular}{|c|c|c|}
\hline Parameters & $\begin{array}{c}\text { For RT Duroid } \\
\text { substrate }\end{array}$ & $\begin{array}{c}\text { For FR4 epoxy } \\
\text { substrate }\end{array}$ \\
\hline Permittivity & -65.9 & -7.29 \\
\hline Permeability & -2.49 & -1.77 \\
\hline Refractive index & -12.83 & -9.39 \\
\hline
\end{tabular}

\section{METAMATERIAL BASED ANTENNA ARRAY DESIGN FOR RT DUROID SUBSTRATE}

\subsection{Circularly polarized $1 \times 2$ square patch antenna array}

The compact circularly polarized $1 \times 2$ square patch antenna array designed and simulated for $0.2 \lambda$ distance between the elements is shown in Figure 2. The plot of return loss, S21, radiation pattern and axial ratio are shown in Figure 3, 4, 5 and 6 respectively. The return loss, $\mathrm{S} 21$, gain and axial ratio values of $-17.25 \mathrm{~dB},-20.23 \mathrm{~dB}, 9.59 \mathrm{~dB}$ and $2.33 \mathrm{~dB}$ respectively are obtained at the resonant frequency.

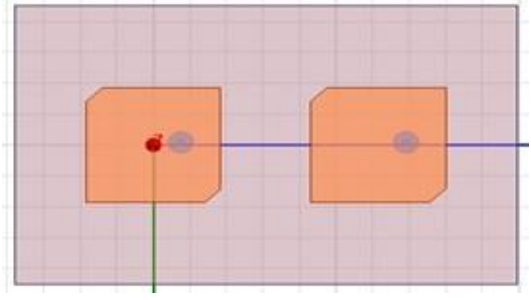

Figure 2: $1 \times 2$ Circularly polarized square patch antenna array

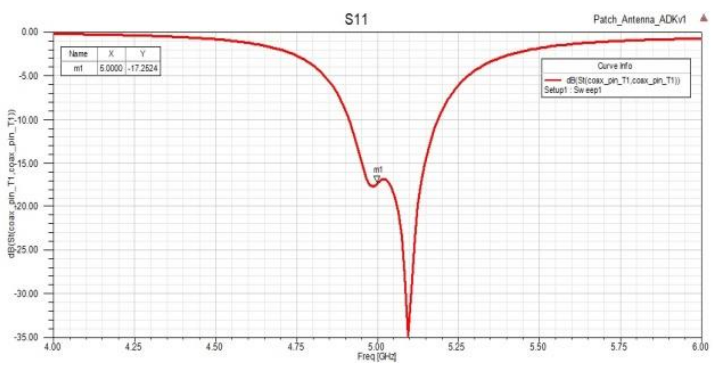

Figure 3: Return loss of $1 \times 2$ circularly polarized square patch antenna array

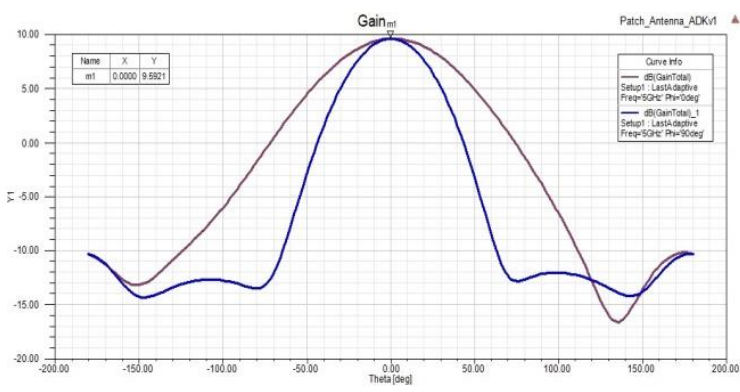

Figure 5: Gain of $1 \times 2$ circularly polarized square patch antenna array

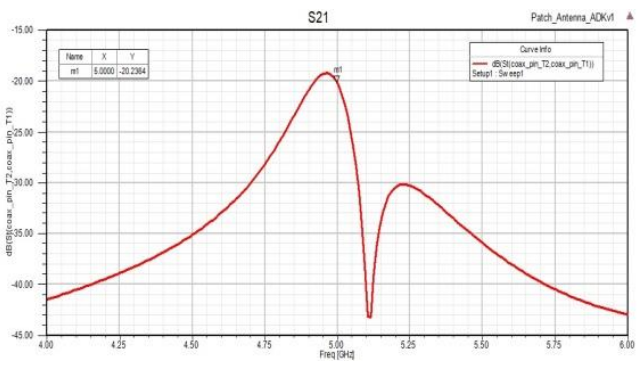

Figure 4: S21 of $1 \times 2$ circularly polarized square patch antenna array

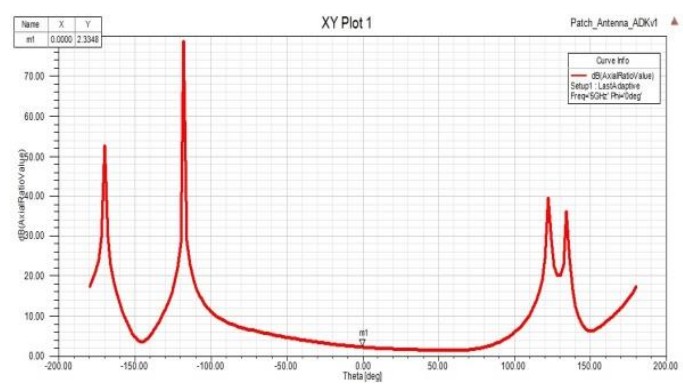

Figure 6: Axial ratio of $1 \times 2$ circularly polarized square patch antenna array 


\subsection{Metamaterial based $1 \times 2$ circularly polarized square patch antenna array}

The Metamaterial based $1 \times 2$ circularly polarized square patch antenna array is shown in Figure 7. An array of metamaterial unit cells is designed by joining 6 DTSRR cells. Two such arrays used for reducing the mutual coupling effect. The return loss, S21, Gain and axial ratio are presented in Figure 8, 9, 10 and 11 respectively. The return loss, S21, gain and axial ratio values of $-16.64 \mathrm{~dB},-26.15 \mathrm{~dB}, 9.48 \mathrm{~dB}$ and $2.4 \mathrm{~dB}$ are respectively obtained at the resonant frequency. The insertion loss reduction of $6 \mathrm{~dB}$ is observed with DTSRR but there is no improvement in the gain as expected.

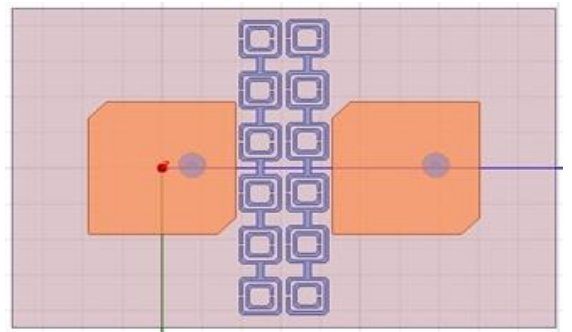

Figure 7: Metamaterial based $1 \times 2$ circularly polarized square patch antenna array

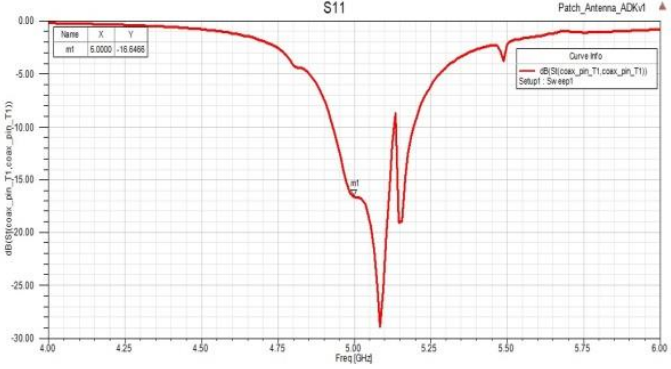

Figure 8: Return loss of Metamaterial based $1 \times 2$ circularly polarized antenna array

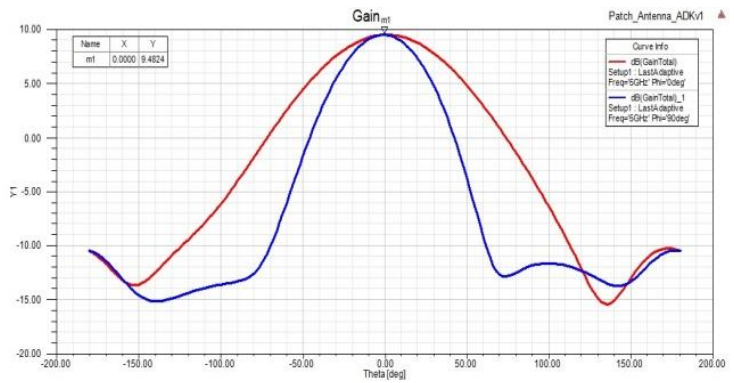

Figure 10: Gain of Metamaterial based $1 \times 2$ circularly polarized antenna array

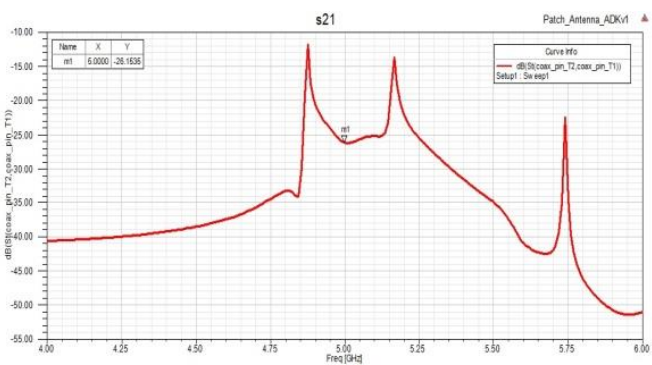

Figure 9: S21 of Metamaterial based $1 \times 2$ circularly polarized antenna array

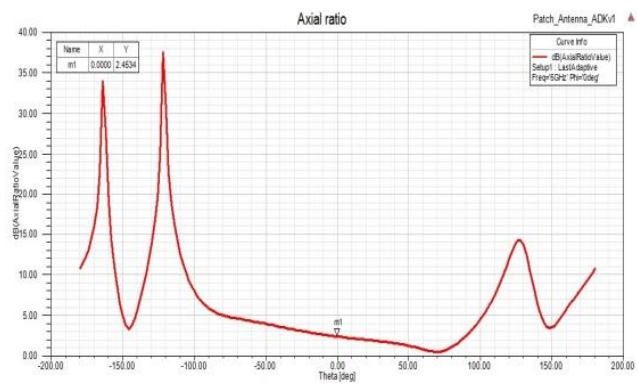

Figure 11: Axial ratio of Metamaterial based $1 \times 2$ circularly polarized antenna array

\section{METAMATERIAL BASED ANTENNA ARRAY DESIGN FOR FR4 EPOXY SUBSTRATE}

\section{1 $1 \times 2$ circularly polarized square patch antenna array}

The compact circularly polarized $1 \times 2$ square patch antenna array designed and simulated for $0.2 \lambda$ distance between the elements is shown in Figure 12 for FR 4 Epoxy substrate. The plot of return loss, S21, radiation pattern and axial ratio are shown in Figure 13, 14, 15 and 16 respectively. The return loss, $\mathrm{S} 21$, gain and axial ratio values of $-12.81 \mathrm{~dB},-18.96 \mathrm{~dB}, 6.65 \mathrm{~dB}$ and $2.05 \mathrm{~dB}$ respectively are obtained at the resonant frequency. 


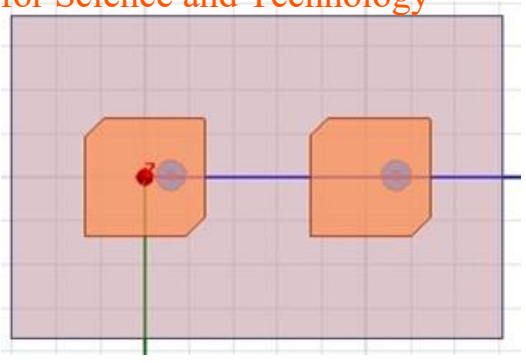

Figure 12: $1 \times 2$ circularly polarized square patch antenna array

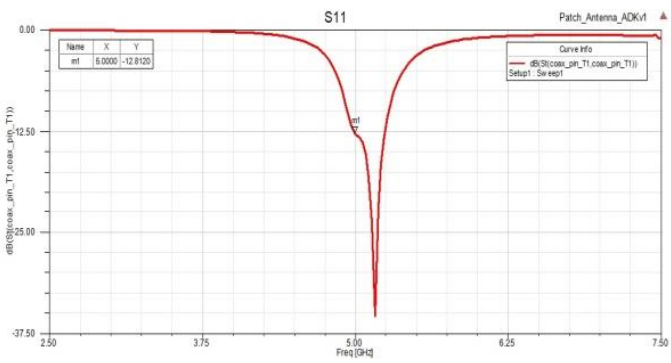

Figure 13: Return loss of $1 \times 2$ circularly polarized square patch antenna array

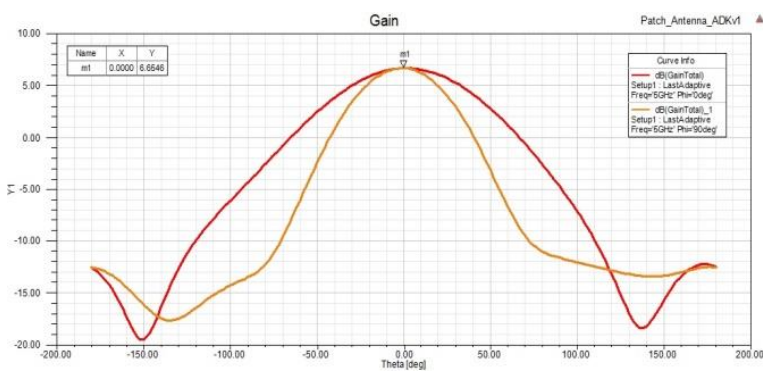

Figure 15: Gain of $1 \times 2$ circularly polarized square patch antenna array

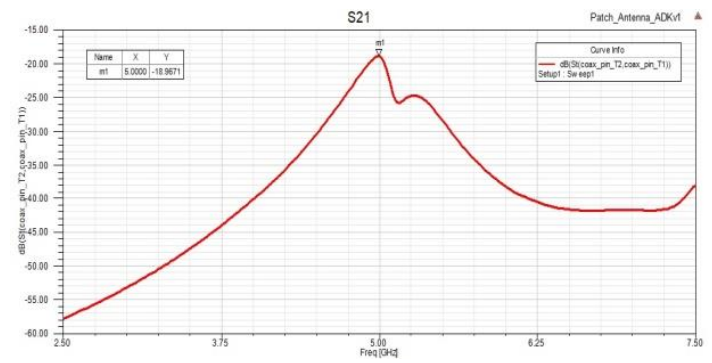

Figure 14: S21 of $1 \times 2$ circularly

polarized square patch antenna array

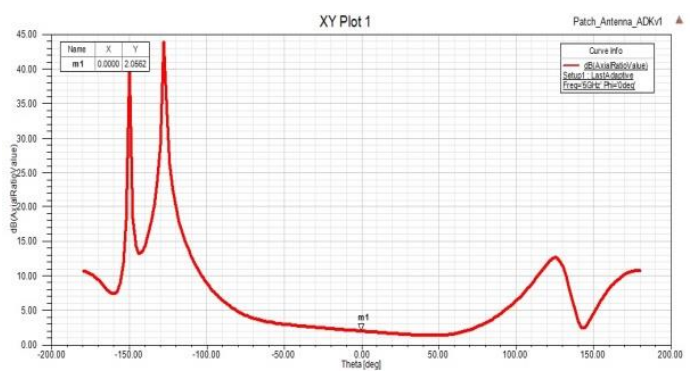

Figure 16: Axial ratio of $1 \times 2$ circularly polarized square patch antenna array

\subsection{Metamaterial based $1 \times 2$ circularly polarized square patch antenna array}

The Metamaterial based $1 \times 2$ Circularly polarized square patch antenna array is shown in Figure 17. An array of DTSRR is designed by joining 6 DTSRR cells to place on the substrate between the patch elements. Two such arrays are used to reduce the effect of mutual coupling. The return loss, S21, Gain and axial ratio are presented in Figure 18, 19, 20 and 21 respectively. The return loss, S21, gain and axial ratio values of $-18.8 \mathrm{~dB},-22.13 \mathrm{~dB}, 6.58 \mathrm{~dB}$ and $2.9 \mathrm{~dB}$ are respectively obtained at the resonant frequency. The mutual coupling reduction of $4 \mathrm{~dB}$ is observed with DTSRR but there is no improvement in the gain as expected. The Table 3 provides the detailed summary of the results.

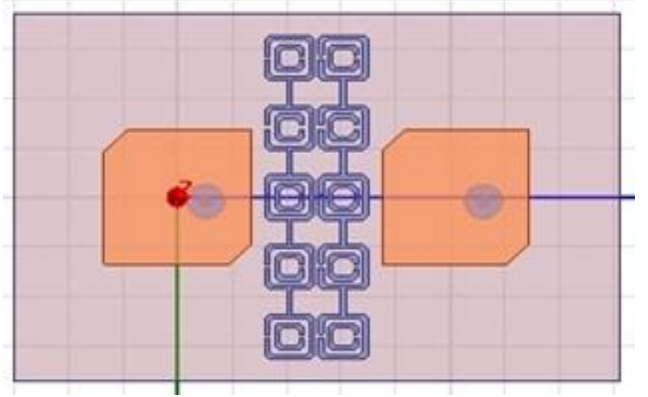

Figure 17: Metamaterial based $1 \times 2$ circularly polarized square patch antenna array 


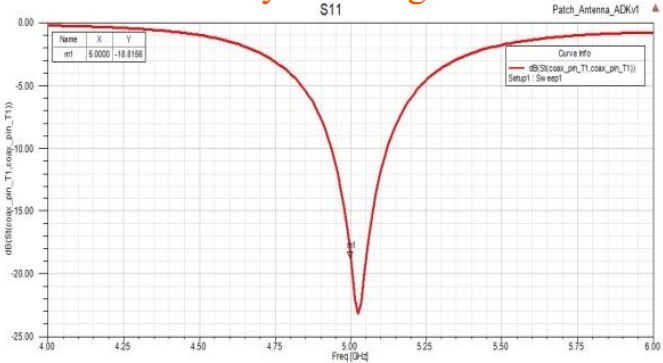

Figure 18: Return loss of Metamaterial based $1 \times 2$ circularly polarized antenna array

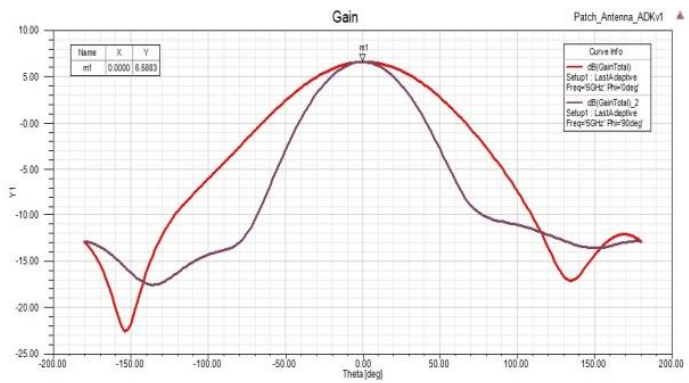

Figure 20: Gain of Metamaterial based $1 \times 2$ circularly polarized antenna array

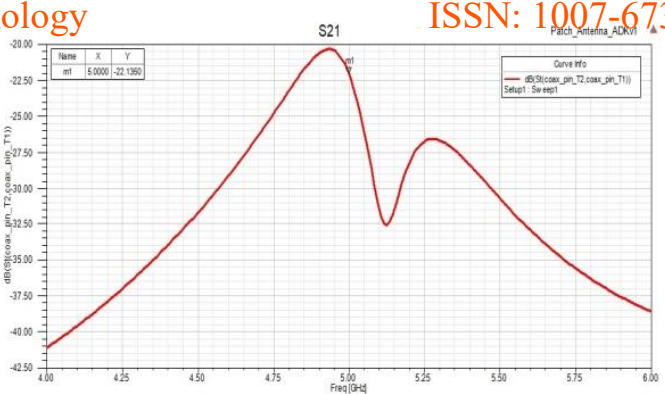

Figure 19: S21 of Metamaterial based $1 \times 2$ circularly polarized antenna array

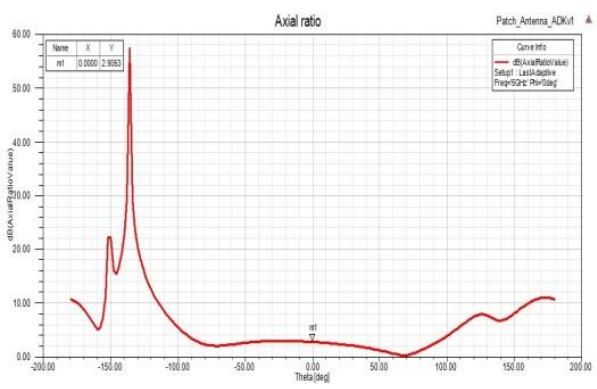

Figure 21: Axial ratio of Metamaterial based $1 \times 2$ circularly polarized antenna array

Table 3: Summary of the results

\begin{tabular}{|c|c|c|c|c|c|}
\hline \multicolumn{2}{|l|}{ Design } & \begin{tabular}{l}
\multicolumn{2}{l}{ Return } \\
loss (in \\
dB)
\end{tabular} & S21 (in dB) & $\begin{array}{l}\text { Gain (in } \\
\text { dB) }\end{array}$ & $\begin{array}{ll}\text { Axial } & \text { ratio } \\
\text { (in } \mathbf{d B}) & \end{array}$ \\
\hline \multirow[t]{2}{*}{$\begin{array}{l}\text { For RT } \\
\text { Duroid }\end{array}$} & $\begin{array}{c}1 \times 2 \text { circularly polarized patch } \\
\text { antenna array }\end{array}$ & -17.25 & -20.23 & 9.59 & 2.33 \\
\hline & $\begin{array}{c}\text { Metamaterial based } 1 \times 2 \\
\text { circularly polarized patch } \\
\text { antenna array }\end{array}$ & -16.64 & -26.15 & 9.48 & 2.4 \\
\hline \multirow[t]{2}{*}{$\begin{array}{l}\text { For FR4 } \\
\text { Epoxy }\end{array}$} & $\begin{array}{c}1 \times 2 \text { circularly polarized patch } \\
\text { antenna array }\end{array}$ & -12.81 & -18.96 & 6.65 & 2.05 \\
\hline & $\begin{array}{l}\text { Metamaterial based } 1 \times 2 \\
\text { circularly polarized patch } \\
\text { antenna array }\end{array}$ & -18.8 & -22.13 & 6.58 & 2.9 \\
\hline
\end{tabular}

\section{CONCLUSION}

As a result of mutual coupling, there exists interference between the electromagnetic waves emitted by the two patches in an antenna array. This is a problem when the antenna arrays are close to each other (distance between the two patches is lesser than 0.5 lambda). This leads to an increase in mutual coupling of the antenna array and also increases the return loss. Thus, if the antenna is made compact by reducing the distance between the patches, the effective gain decreases and the losses are higher. This is prevented to a large extent by the use of the metamaterial designs for mutual coupling reduction. In this work, comparison of circularly polarized antenna for two types of substrates is carried out. The diagonally truncated Metamaterial is designed and verified using MATLAB and then the array of DTSRR is used between the patch elements. With RT Duroid substrate the mutual coupling reduction is less at $5 \mathrm{GHz}$ as compared to FR4 Epoxy substrate.

\section{ACKNOWLEDGEMENT}

The authors would like to thank RV College of engineering for providing the simulation resources to carry out the research work. 


\section{REFERENCES}

[1] F. Yang and Y. Rahmat-Samii, "Microstrip antennas integrated with electromagnetic band- gap (EBG) structures: a low mutual coupling design for array applications," IEEE trans. antennas propagation, vol. 51, no. 10, pp. 2936-2946, Oct. 2003.

[2] C.A Balanis, "Antenna Theory Analysis and Design," John Wiley and Sons Inc., 2nd Edition, New York, 2005.

[3] G. Vesalago, "The electrodynamics of substances with simultaneously negative values of $\epsilon$ and $\mu$," soviet phys USPEKI, vol. 10, no. 4, pp. 509-514, 1968.

[4] D. R. Smith, D. C. Vier, Th. Koschny and C. M. Soukoulis "Electromagnetic parameter retrieval from inhomogeneous metamaterials," the american physical society, 2005.

[5] M. Nikolic, A. Djordjevic and A. Nehorai, "Microstrip antennas with suppressed radiationin horizontal directions and reduced coupling," IEEE trans. antennas propagation, vol. 53, no. 11, pp. 3469-3476, Nov. 2005.

[6] D.R. Smith, W.J. Padilla, D.C. Vier, et al, "Composite medium with simultaneously negative permeability and permittivity,” Phys Rev Lett 84 (2000), 4184-4187.

[7] Ahmad B. Numan and Mohammad S. Sharawi "Extraction of material parameters for metamaterials using a full-wave simulator," IEEE antennas and propagation magazine, vol. 55, no. 5, October 2013.

[8] Yang H.Y, Alexopoulos N.G, Yablonovitch E, "Photonic band-gap materials for high-gain printed circuit antennas”, IEEE Trans. on Antennas Propag., 1997, vol. 45, no.1, pp. 185- 187.

[9] R. Garg, P. Bhartia, I. Bahl and A. Ittipiboon, "Microstrip Antenna Design Handbook", Norwood, MA: Artech House, 2001.

[10] Mohammed M. Bait-Suwailam, Omar F. Siddiqui, and Omar M. Ramahi, "Mutual Coupling Reduction Between Microstrip Patch Antennas Using Slotted-Complementary Split-Ring Resonators", IEEE Antennas Wireless Propag. Lett, 2010, vol. 9, pp. 876 - 878. 